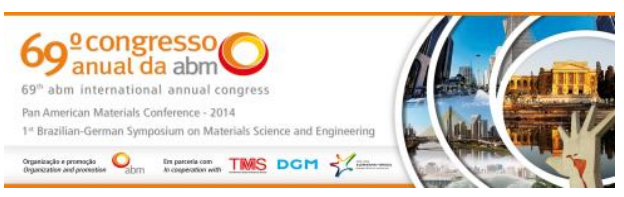

Tema: Fundição

\title{
AVALIAÇÃO DO COMPORTAMENTO MICROESTRUTURAL E DE MICRODUREZA EM MATRIZ DE ALUMINIO COM INCLUSÃO DE NANOTUBO DE CARBONO E NÍQUEL*
}

\author{
Luiz Gabriel da Silva Nascimento ${ }^{1}$ \\ José Antônio da Silva Souza² \\ Fernando Antônio de Sá ${ }^{3}$
}

\section{Resumo}

Um material que vem sendo muito estudado quando imerso na matriz de outros materiais, são os nanotubos de carbono, uma forma alotrópica do carbono, que são milhares de vezes mais finos que um fio de cabelo, mas que apesar disso, possuem uma extraordinária resistência mecânica. O alumínio por apresentar um baixo peso específico e ter a facilidade de se unir a outros materiais pode nos fornecer excelentes propriedades e muitas aplicações tecnológicas. Através de ensaios metalográficos e mecânico, esse trabalho avaliou o comportamento microestrutural e de microdureza do alumínio depois da adição nanotubo de carbono e nanotubo mais níquel em sua estrutura. Foi usado um processo de fabricação por fusão com agitação mecânica por um pequeno motor elétrico e resfriamento brusco por água. Depois das análises nesses diversos materiais, com composição diferenciada, o que melhor apresentou propriedade mecânica foi o $\mathrm{Al}-3 \% \mathrm{Ni}+$ nanotubo de carbono. Palavras-chave: Nonotubo de carbono; Alumínio; Níquel; Microdureza.

\section{MICROSTRUCTURAL AND MECHANICAL ANALYSIS OF ALUMINUM MATRIX WITH INCLUSION OF NICKEL AND CARBON NANOTUBE}

\begin{abstract}
A material that has been widely studied when immersed into other materials matrices are carbon nanotubes, an allotropic form of carbon that is thousands of times thinner than a human hair, but which have an remarkable mechanical resistance. Since aluminum has low specific weight and can easily bond to other materials, it can provide excellent properties and many technological applications. By means of metallographic and mechanical tests, this work evaluates the microstructural behavior and microhardness of aluminum after the addition of carbon nanotubes and nickel to its structure. We adopted the manufacturing process by fusion with mechanical agitation by a small electric motor e quenching by water. After the analyses of these materials, which had varied compositions, the one which presented the best mechanical property was $\mathrm{Al}-3 \% \mathrm{Ni}+$ carbon nanotube.
\end{abstract}

Keywords: Carbon nanotube; Aluminum; Nickel; Microhardness.

1 Engenheiro Mecânico, Mestre em Engenharia Mecânica, Professor, Instituto Federal de Educação, ciência e Tecnologia do estado do Pará (IFPa), Marabá, PA, Brasil; luiz.nascimento@ifpa.edu.br

2 Engenheiro Químico, Mestre em Engenharia Materiais e metalurgia, Doutor, Professor Associado, Universidade Federal do Pará,Belém, PA, Brasil; jass@ufpa.br.

3 Engenheiro Metalúrgico, Mestre em Engenharia Metalúrgica, Doutor, Professor associado II, Universidade Federal do Pará,Belém, PA, Brasil; as@ufpa.br.

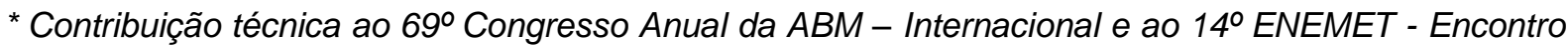
Nacional de Estudantes de Engenharia Metalúrgica, de Materiais e de Minas, 21 a 25 de julho de 2014, São Paulo, SP, Brasil. 


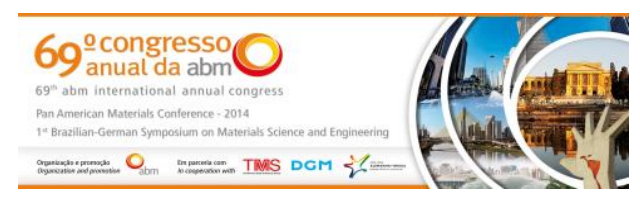

\section{INTRODUÇÃO}

Pesquisas na atualidade têm visado obter materiais que possam satisfazer mais adequadamente as necessidades da engenharia. Os materiais metálicos são aqueles que nos fornecem boas propriedades, sejam elétricas, mecânica, físicas, químicas etc. Nesse contexto o alumínio por apresentar um baixo peso específico, e quando aliado a outros materiais é capaz de agregar boas propriedades. Diante disso, pesquisa a nível mundial tem estudado esse elemento, ligado ou não com outros materiais. Para que a junção de dois ou mais materiais venham resultar em boas propriedades, é necessário que haja afinidade a nível microestrutural, que se revela a nível macroestrutural. Um elemento como nanotubo de carbono adicionado ao alumínio pode mudar as propriedades deste material, visando propriedades específicas.

A região amazônica tem grandes reservas de bauxita, minério de onde é retirado esse material, sendo que no estado do Pará e Maranhão a cadeia extrativa do alumínio ocorre inclusive com a produção de ligas em forma de cabos. Atualmente encontra-se em nível inicial de produção nos laboratórios da Eletronorte Belém a produção de nanotubos de carbono. Esta inovação tecnológica composta por nanotubo de carbono e alumínio, provavelmente pode ter propriedades mecânicas, elétricas e outras diferenciadas, que poderão ser utilizadas para diversas aplicações industriais, gerando novos recursos materiais que poderão ser utilizados a nível nacional.

Várias referências mostram aplicações dos nanotubosde carbobo, por suas boas propriedades conforme Barros [1], Reis [2], Corrêa Jr [3], Saito [4], Silva [5]. O estudo de propriedades físicas, mecânicas, elétricas em matriz de alumínio, é novo, onde o conhecimento de solidificação, metalurgia física, propriedades dos materiais é muito importante. Espera-se que os nanotubos se comportem difundindo para espaços das redes cristalinas termodinamicamente favoráveis.

O conhecimento levantado no estudo da aplicação de nanotubo em matriz de alumínio pode implicar em grandes aplicações industriais, como confecção de cabos para condução de energia elétrica, pois pode-se ter um material bastante resistente que tenha boas propriedades mecânicas e elétricas, com menos perdas do que cabos usados atualmente e grande transmissão de energia com cabos de diâmetros menores.Cabos de alumínio com nanotubos de carbono reduzem perdas de eletricidade. Uma pesquisa feita no Centro de Engenharia de Nanoprodutos da Fundação Educacional Inaciana Padre Sabóia de Medeiros (FEI) testou um cabo de alumínio com nanotubos de carbono que aumenta a condutividade elétrica em 170 vezes e reduz as perdas de energia em até $65 \%$ em relação aos cabos de alumínio tradicionais, Alcântara [6].

\section{METODOLOGIA}

\subsection{Preparações dos Materiais}

Para fabricar o material pesquisado nesse trabalho, usou-se alumínio comercialmente puro, com cerca de $99,73 \%$ de pureza, atestado através de caracterização química feita em um espectrômetro de massa, disponibilizado pela Alubar Cabos S.A., localizada na cidade de Barcarena, Pará. O espectrômetro encontra-se conectado a um computador e através deste, utilizando-se de um

* Contribuição técnica ao 69 Congresso Anual da ABM - Internacional e ao 14ํㅡㄹ ENEMET - Encontro Nacional de Estudantes de Engenharia Metalúrgica, de Materiais e de Minas, 21 a 25 de julho de 2014, São Paulo, SP, Brasil. 


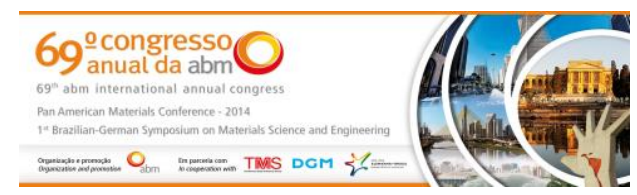

software adequado, fornece a composição química do material. O nanotubo de carbono foi fornecido Empresa Eletronorte, sendo esse o nanotubo de paredes múltiplas. Foi primeiramente feito duas ligas de alumínio níquel, alumínio comercialmente puro, uma de alumínio com $1 \%$ de níquel e outra com $3 \%$. Os materiais estão dispostos na tabela abaixo.

Tabela 1: Materiais processados

\begin{tabular}{c|l}
\hline Ordem & \multicolumn{1}{c}{ Material } \\
\hline 1 & Alumínio $+3 \%$ Níquel + Nanotubo de Carbono \\
2 & Alumíno + 1\% de Níquel + Nanotubo de Carbono \\
3 & Alumínio puro + Nanotubo Carbono \\
4 & Alumínio Puro \\
\hline
\end{tabular}

A quantidade de nanotubo na matriz não excedeu1\%, sendo que a quantidade de nanotubo no alumínio puro foi maior do que a nos demais materiais. Depois de fabricado por fusão nesses materiais, foram feitos cortes que não ultrapassaram a secção transversal de pequenas peças cilíndricas de altura e diâmetro respectivamente de 2 e $3 \mathrm{~cm}$. Depois disso, nesses cortes as peças foram abertas usando ferramentas especificas, e logo após foram inseridas as porções de nanotubo de carbono em alumínio puro e alumínio com níquel. Afigura 01, mostra como foi adicionado o nanotubo nas peças e logo depois de inseridas na lingoteira, que por sua vez foi deslocada ao forno.

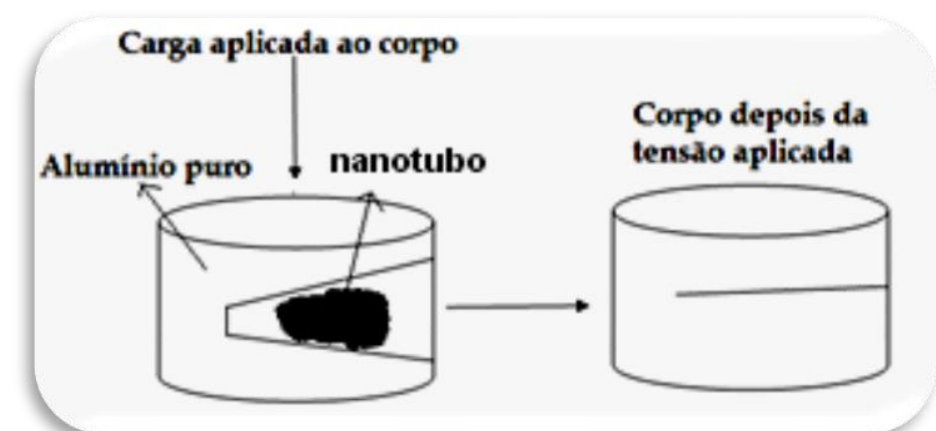

Figura 1. Método de fabricação do material, inclusão do nanotubo de carbono e aplicação de uma carga, antes da fusão.

\subsection{Fusão dos Materiais de Estudo}

Projetou-se uma lingoteira, exclusiva para criar os materiais estudados no trabalho, figura 2. A mesma foi fabricada de aço e possuía quatro cilindros vazados, não passantes, que foram soldados em uma base de perfil retangular, para que dentro deles fossem inseridas as peças que seriam fundidas. A lingoteira possuia um comprimento de aproximadamente $30 \mathrm{~cm}$ e cada cilindro $4 \mathrm{~cm}$ de altura e $3 \mathrm{com}$ de diâmetro, dois furos laterais um para entrada e saída de água. Esse líquido escoava por dentro do perfil impondo um resfriamento brusco ao material, pois não era desejada a precipitação dos elementos da matriz de alumínio.

A lingoteira foi ao forno a uma temperatura de aproximadamente $750 \stackrel{\circ}{\circ}$ permanecendo lá até a completa fusão do material. Com um tenaz retirou-se do forno a lingoteira e o material foi agitado manualmente com uma vara metálica

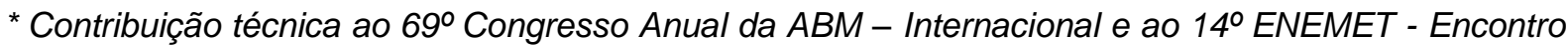
Nacional de Estudantes de Engenharia Metalúrgica, de Materiais e de Minas, 21 a 25 de julho de 2014, São Paulo, SP, Brasil. 


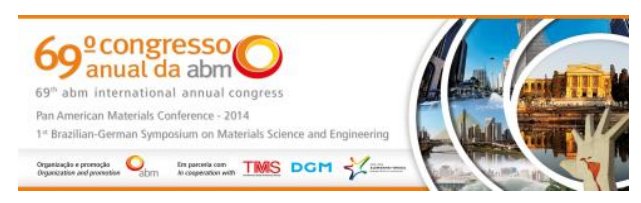

recoberta por alumina com o objetivo de misturar parcialmente as amostras e não contaminar o material. A lingoteira foi novamente levada ao forno e depois de 10 minutos retirada, foi executado um novo processo de agitação mecânica, com o intuito de homogeneizar completamente o material. Esse consistiu em usar um pequeno motor elétrico de 5 volts, e rotação elevada e nele acoplado um eixo de 120 $\mathrm{mm}$ de altura e $2 \mathrm{~mm}$ de diâmetro. Em sua extremidade havia uma pequena hélice, que quando em funcionamento agitava o material. $O$ eixo rotativo permaneceu pelo menos dez segundos agitando o material.

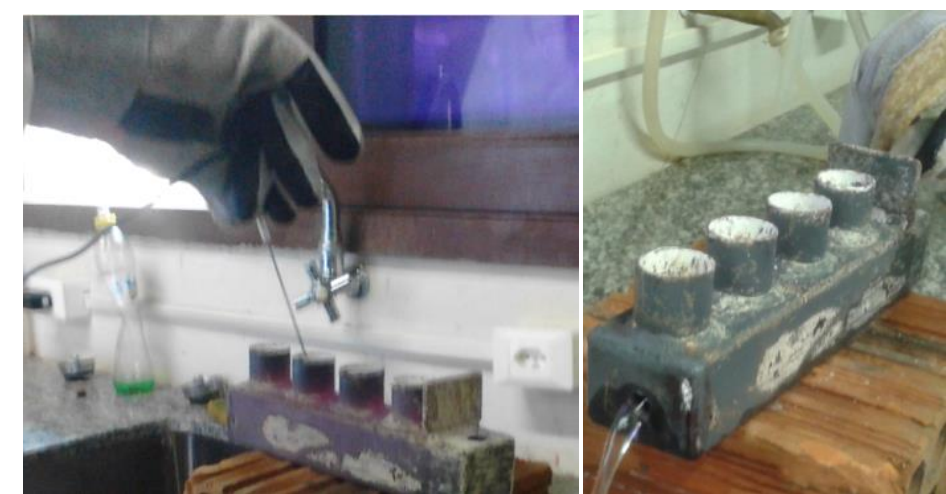

Figura 2. Lingoteira com furos para entrada e saída de água e cilindros onde foram fundidos os materiais.

\subsection{Ensaio Metalográfico}

Retirou-se os pequenos lingotes de forma cilíndrica, após a completa solidificação dos materiais, os lingotes foram seccionados longitudinalmente e foram submetidos ao processo de polimento. Lixas granulométricas diversas foram usadas para o polimento das superfícies das amostras. Essas foram polidas em uma lixadeira manual, em uma sequencia de granulometria variando de 80 até 600 mesh, diferenciando a direção de lixamento em noventa graus para cada novo lixamento, até a última lixa para conseguir uma superfície adequada para a revelação das estruturas, sem a presença de riscos. Em seguida a superfície polida foi atacada quimicamente, com uma solução aquosa ácida de $5 \mathrm{ml} \mathrm{HF}, 30 \mathrm{ml} \mathrm{HNO}, 60 \mathrm{ml} \mathrm{HCL}$ e $5 \mathrm{ml} \mathrm{H}_{2} \mathrm{O}$ e revelada a macroestrutura e microestrutura do material.

\subsection{Realização do Ensaio de Dureza}

A microdureza pode fornecer dados importantes sobre a resistência de um material, para quantificar essa propriedade, foi lançado mão de um microdurômetro marca Digital Metallic Vickers Hardness TH-710, pertencente ao curso técnico em mecânica do Instituto Federal de Educação, ciência e Tecnologia do Estado do Pará-IFPa- campus Marabá industrial. A amostra foi preparada e colocada na base de sustentação do microdurômetro, a carga de ensaio selecionada e o tempo, então aplicada sobre a área de medição de acordo com a norma do ensaio, feitos sobre mesmas condições para todos os materiais ensaiados. Foram realizadas cinco penetrações em cada corpo de prova em pontos aleatórios da superfície do material. Depois das medições das diagonais os dados foram coletados e disposto em uma tabela para análise da resistência dos materiais. A figura 3 mostra a geometria da indentação deixada pelo penetrador do aparelho de medição de microdureza.

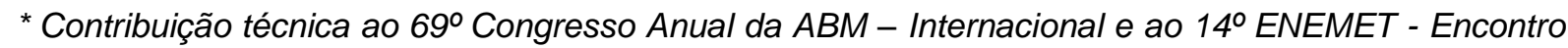
Nacional de Estudantes de Engenharia Metalúrgica, de Materiais e de Minas, 21 a 25 de julho de 2014, São Paulo, SP, Brasil. 


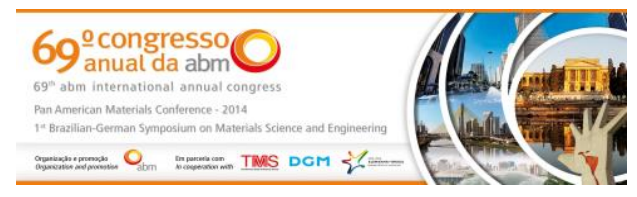

Figuras 3. Penetração feita durante o ensaio de microdureza no material. (400x)

\section{RESULTADOS E DISCUSSÃO}

\subsection{Macroestrutura}

As macroestruturas reveladas nos lingotes após solidificação e ataque químico é predominantemente colunar, essa região é caracterizada por dendritas orientadas concordando com Garcia [7]. não revela zonas coquilhadas, o que poderia ocorrer se o material solidificando perdesse calor significantemente para as laterais do recipiente, se as mesmas estivessem frias, o que não é o caso do experimento, uma vez que a solidificação foi forçada e a parede se encontrava com a mesma temperatura do material quando retirada do mufla, mas também não é observada uma única direção dos grãos, isso se deve ao fato da parede da lingoteira perder calor para o ambiente.

Os grãos não possuem tamanhos definidos, podemos enxergar grãos bem pequenos e outros bem volumosos. Nas imagens das macroestruturas, figura 4, os grãos estão tendendo a crescer verticalmente, direção para onde possivelmente poderia está direcionada parte dos gradientes de temperatura, porque o resfriamento foi feito pela base da lingoteira.
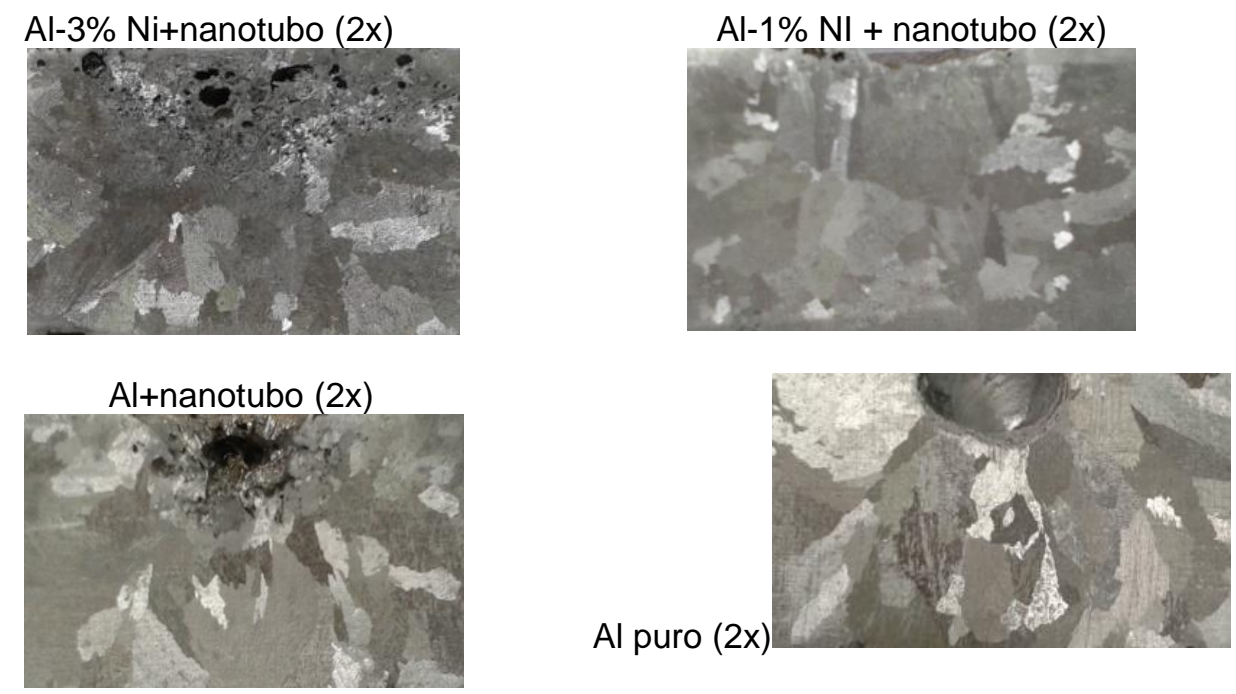

Figura 4. Imagens das macroestrutras reveladas após ataque químico.

* Contribuição técnica ao $69^{\circ}$ Congresso Anual da ABM - Internacional e ao 14ํㅡㄹ ENEMET - Encontro Nacional de Estudantes de Engenharia Metalúrgica, de Materiais e de Minas, 21 a 25 de julho de 2014, São Paulo, SP, Brasil. 


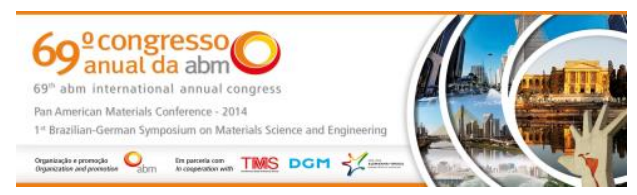

\subsection{Microestrutura}

As morfologias das microestruturas são de estruturas dendriticas, como observado na figura 5. O Al-3\% Ni+nanotubo apresentou braços dendriticos mais refinados já Al $1-\mathrm{NI}+$ nanotubo ramificações mais grosseiras. $\mathrm{O}$ al+ nanotubo também apresentou crescimento dendritico com ramos medianos.

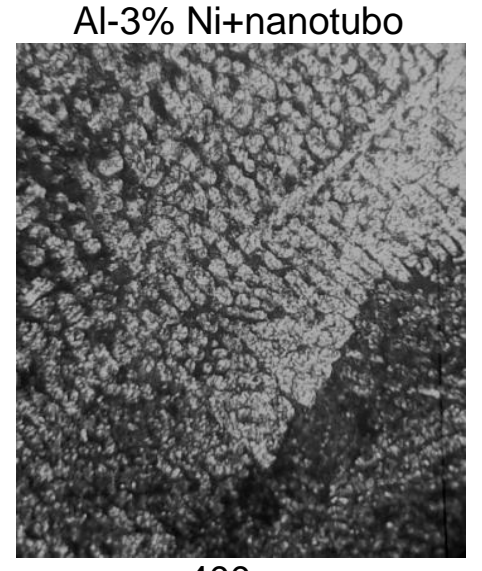

$400 x$

Dendritas com braços finos

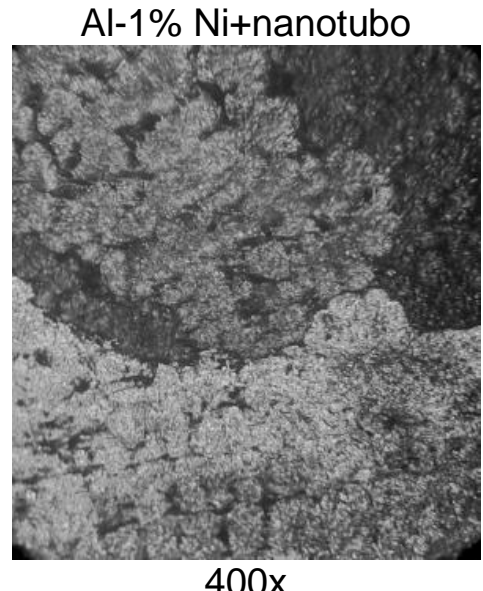

$400 x$

Dendritas com braços grossos

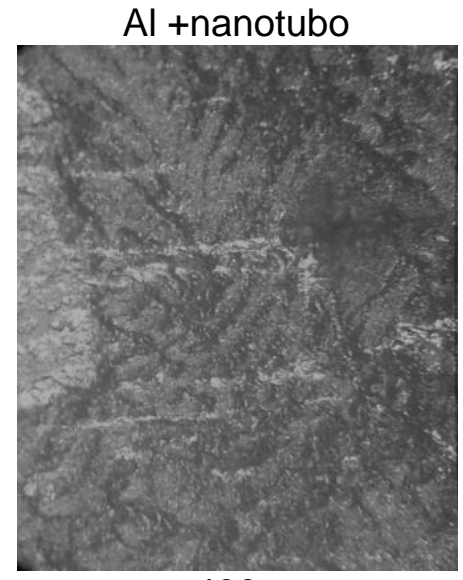

$400 x$

Dendritas com braços finos

Figura 5. Microestruturas reveladas após ataque químico.

Posteriormente foram feitas na peça 1, análises semi-qualitativas, que permite estimar o comportamento químico e estrutural do material, através de microscopia eletrônica de varredura - MEV e extraídas imagens que revelam um material de duas fases distintas dentro das dendritas. Uma fase mais escura, de acordo com spectrum 1, é rica em peso de nanotubo, e uma fase clara, spectrum 2, rica em níquel e está disposta como camadas. As duas fases possuem imersas em suas estrururas tanto nanotubo como níquel. figura 6.

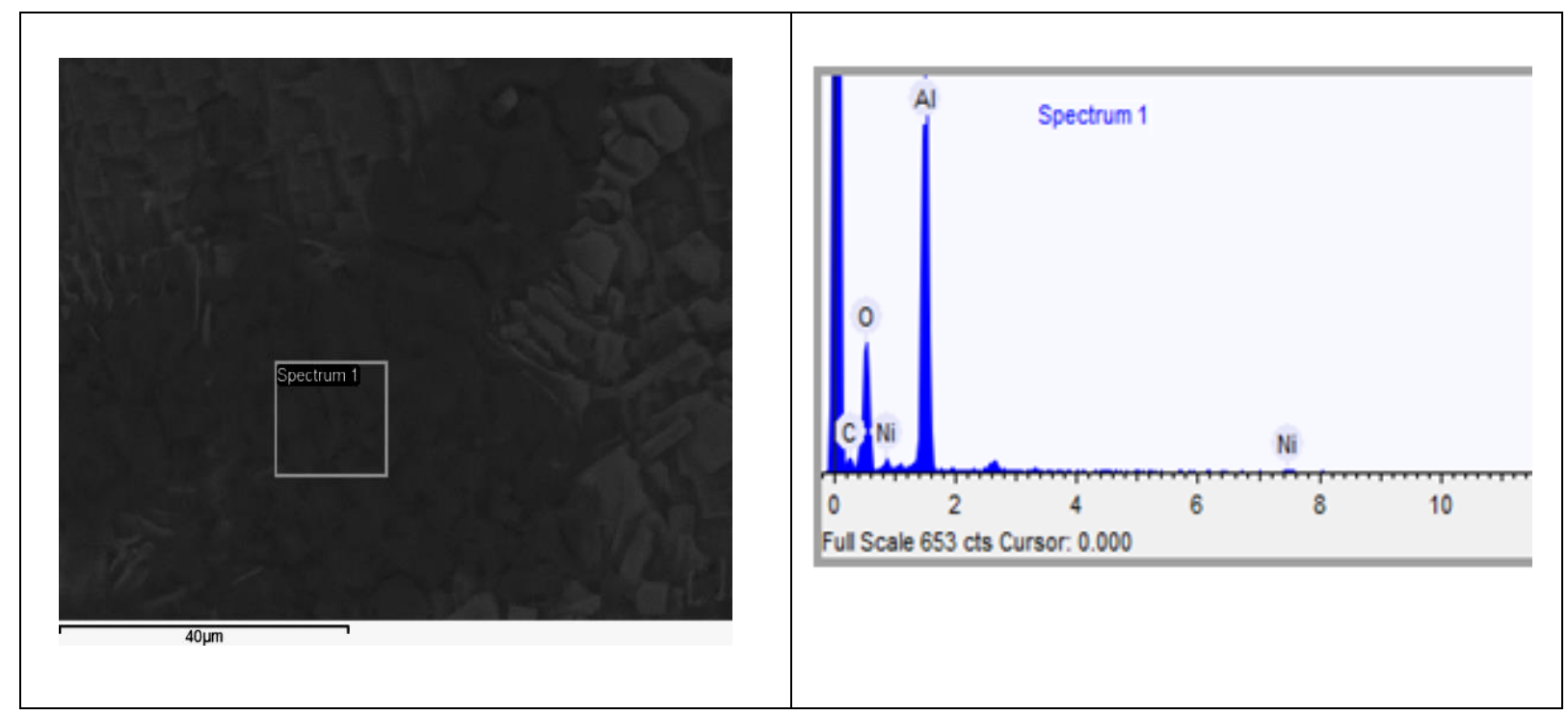

* Contribuição técnica ao 69 Congresso Anual da ABM - Internacional e ao 14 ENEMET - Encontro Nacional de Estudantes de Engenharia Metalúrgica, de Materiais e de Minas, 21 a 25 de julho de 2014, São Paulo, SP, Brasil. 

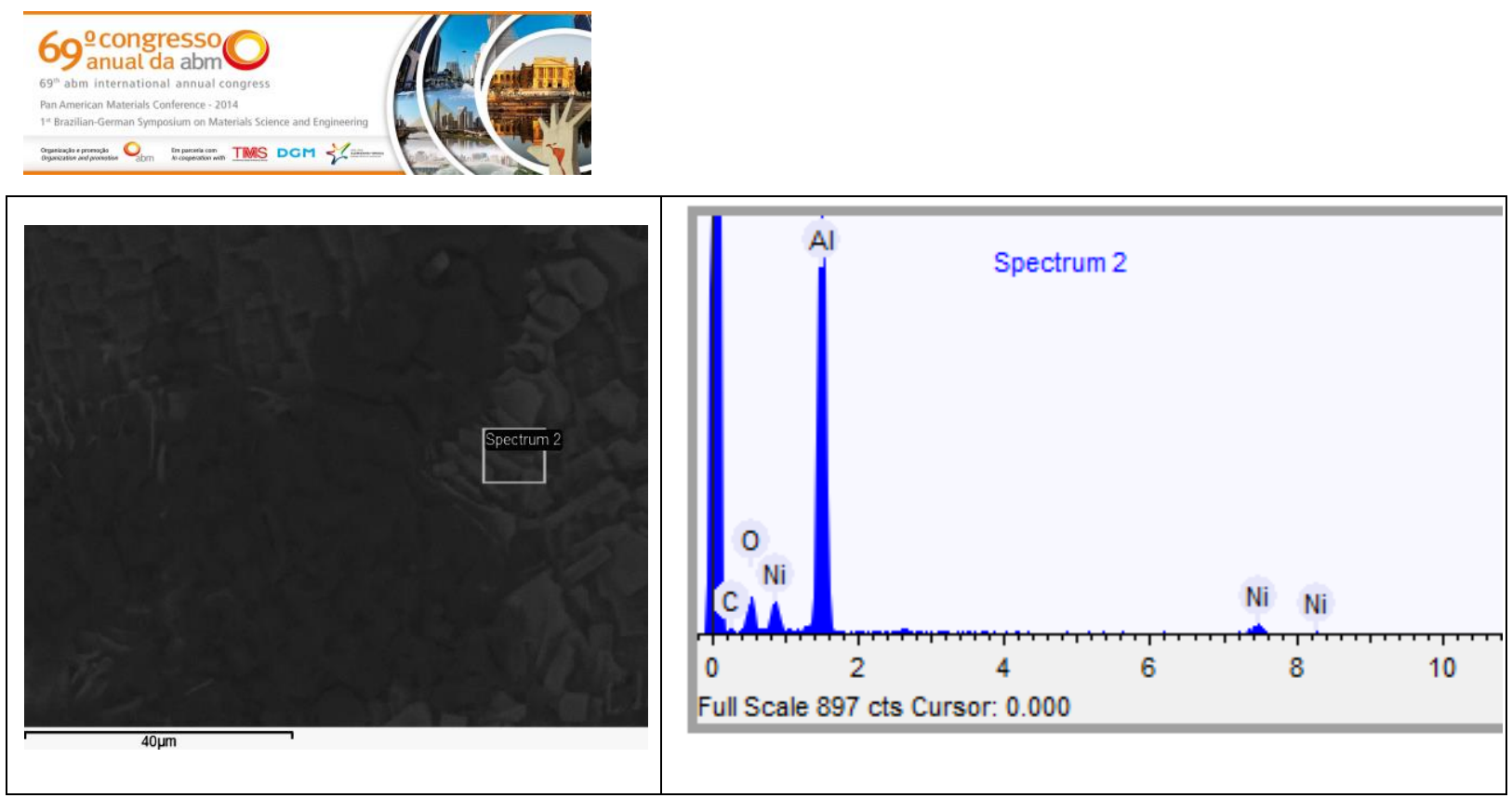

Figura 6. MEV peça 1, revela duas fases dentro da dendrita, uma mais clara rica em níquel e outra mais escura rica em nanotubo. 2000x

\subsection{Microdureza}

Com Intuito de caracterizar mecanicamente os materiais, foi realizado ensaio de microdureza. $\mathrm{Na}$ tabela 2 abaixo estão os dados, os valores de microdureza para cada material não diverge significativamente, tendo um desvio padrão relevante, o que implica em um material bem homogêneo. Vemos na tabela que o teor de níquel e de nanotubo na matriz de alumínio influencia na resistência do material [8]. Eles se agregam na matriz e em espaços favoráveis, o que pode está implicando no aumento de resistência. Para o CDP-1, que tem aproximadamente $3 \%$ em níquel e nanotubo de carbono, nota-se um aumento em mais de $200 \%$ na propriedade mecânica. O CDP-2, que apresenta somente nanotubo na matriz de alumínica, quase dobrou a resistência do alumínio. Dados mostrados na tabela de microdureza, tabela 1.

A figura 7 é um gráfico, que mostra a evolução da resistência mecânica, microdureza com acréscimo de níquel e nanotubo de carbono no alumínio.

Tabela 02. Dados de microdurezas extraídos no ensaio.

\begin{tabular}{cccccccc}
\hline MATERIAIS & $\begin{array}{c}\text { DUREZA } \\
1(\mathrm{HV})\end{array}$ & $\begin{array}{c}\text { DUREZA } \\
2(\mathrm{HV})\end{array}$ & $\begin{array}{c}\text { DUREZA } \\
3(\mathrm{HV})\end{array}$ & $\begin{array}{c}\text { DUREZA } \\
4(\mathrm{HV})\end{array}$ & $\begin{array}{c}\text { DUREZA } \\
5(\mathrm{HV})\end{array}$ & MÉDIA & $\begin{array}{c}\text { Desvio } \\
\text { padrão }\end{array}$ \\
\hline $\begin{array}{c}\text { Al-3\% } \\
\text { Ni+Nanotubo }\end{array}$ & 179,11 & 180,43 & 189,67 & 196,57 & 203,38 & 189,83 & 9,30 \\
$\begin{array}{c}\text { Al-1\%Ni+ } \\
\text { nanotubo }\end{array}$ & 134,31 & 137,51 & 132,61 & 131,61 & 132,33 & 133,67 & 2,11 \\
$\begin{array}{c}\text { Al + } \\
\text { Nanotubo }\end{array}$ & 134,89 & 124,33 & 143,63 & 139,00 & 136,48 & 135,67 & 6,39 \\
Al Puro & 95,80 & 84,46 & 92,61 & 77,56 & 85,51 & 87,18 & 6,43 \\
\hline
\end{tabular}

* Contribuição técnica ao 69 Congresso Anual da ABM - Internacional e ao 14 ENEMET - Encontro Nacional de Estudantes de Engenharia Metalúrgica, de Materiais e de Minas, 21 a 25 de julho de 2014, São Paulo, SP, Brasil. 


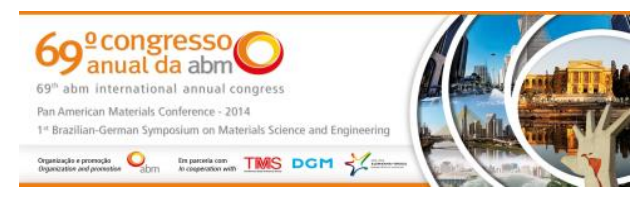

\section{Aumento da Micrudureza em relação a concentração de Nanotubo de Carbono e Níquel}

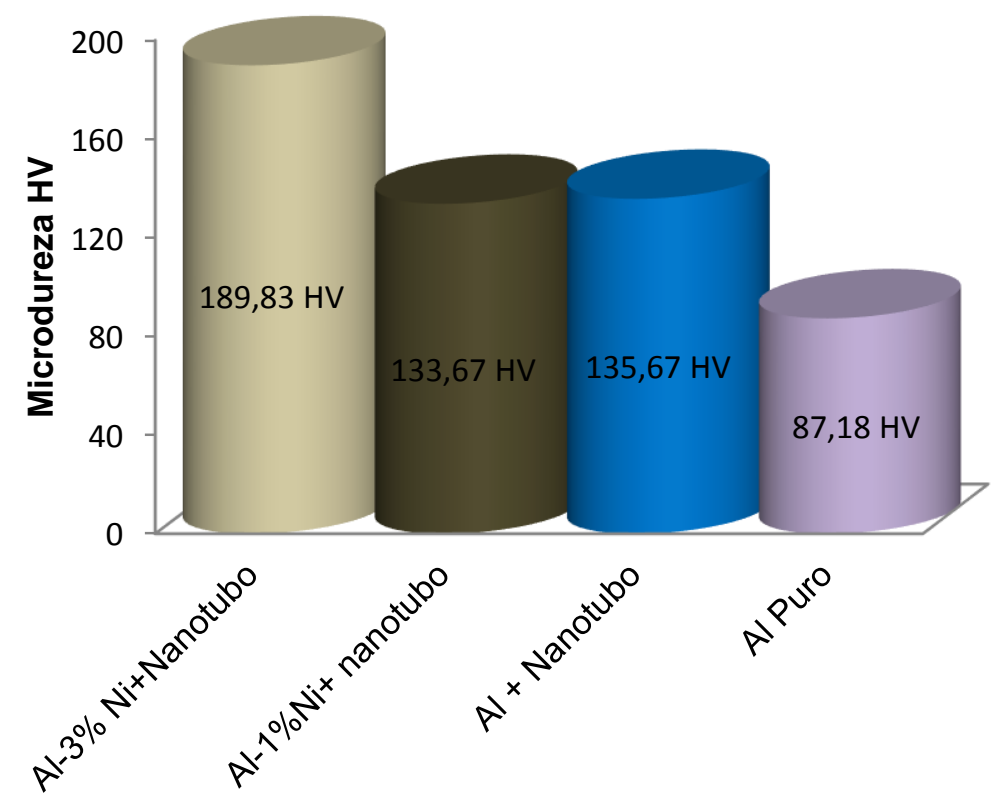

Materiais estudados

Figura7. Aumento dos valores de microdureza com a adição de níquel e nanotubo na atriz de alumínio.

\section{CONCLUSÕES}

A Metodologia usada nesse trabalho permitiu fazer análises microestruturais e mecânicas, que implicam nas seguintes conclusões:

- As morfologias das macroestruturas são predominantemente colunar.

- As microestruturas após fusão e solidificação dos materiais aqui estudados, são bem distintas, o $\mathrm{Al}-3 \% \mathrm{Ni}+$ nanotubo apresenta ramificações dendríticas mais refinadas que o $\mathrm{Al}-1 \% \mathrm{NI}+$ nanotubo, que por sua vez vem apresentar braços mais grossos.

- O Al-1\% $\mathrm{NI}$ + nanotubo, apresentou, aparentemente, grãos maiores que o Al$3 \% \mathrm{Ni}+$ nanotubo.

- Os materiais com alumínio, nanotubo de carbono mais níquel, apresentaram em sua estrutura fases escuras, ricas em nanotubo de carbono e fases claras ricas em níquel dispostas em camadas.

- A adição de níquel na matriz de alumínio aumenta a resistência, se maior a quantidade de níquel, maior a microdureza.

- Dentre todos os materiais estudados o Al-3\% Ni+nanotubo foi o que apresentou melhor resistência mecânica.

* Contribuição técnica ao $69^{\circ}$ Congresso Anual da ABM - Internacional e ao 14ํㅡㄹ ENEMET - Encontro Nacional de Estudantes de Engenharia Metalúrgica, de Materiais e de Minas, 21 a 25 de julho de 2014, São Paulo, SP, Brasil. 


\section{REFERÊNCIAS}

1 Barros BE. Propriedades Eletrônicas e Mecânicas de Nanomateriais de Carbono. In: 5oㅡ Encontro da Rede Nacional de Pesquisa em Nanotubos de Carbono; 2010; Fortaleza, Brasil. Fortaleza: Departamento de Física, Universidade Federal do Ceará; 2010.

2 Reis MA, Del Nero J. Processo de sintese do nanocomposito de aluminio e nanotubos de carbono, nanocompositos assim obtidos e seu uso como sensor termopiezoresistivo. Instituto Nacional da Propriedade Industrial - INPI; Protocolo:0106/10 INPI-PA; 2010.

3 Corrêa Jr. A, Fillipov MDO, Rodrigues L, Fortes ICP, Pinto FF. Possíveis utilizações de nanotubos de carbono na produção de biodiesel. In: 5ํㅡㄹ Encontro da Rede Nacional de Pesquisa em Nanotubos de Carbono; 2010; Fortaleza, Brasil. Fortaleza: Departamento de Física, Universidade Federal do Ceará; 2010.

4 Saito R, Dresselhaus G, Dresselhaus MS. Physical properties of carbon nanotubes. Londres: Imperial College Press; 1998.

5 Silva GG. Desenvolvimento de compósitos poliméricos com nanomateriais de carbono. In: 5ํㅡㄹ Encontro da Rede Nacional de Pesquisa em Nanotubos de Carbono. 2010; Fortaleza, Brasil. Fortaleza: Universidade Federal do Ceará; 2010.

6 Alcântara AS. Cabos de alumínio com nanotubos reduzem perdas de eletricidade. Agência Fapesp. 29 jan. 2009 [acesso em 11 jan. 2014]. Em: http://www.inovacaotecnologica.com.br/noticias/noticia.php?artigo=cabos alumínionanotubos-carbono-perdas-eletricidade\&id=.

7 Garcia A. Solidificação: fundamentos e aplicações. São Paulo: Ed. Unicamp; 2001.

8 Canté MV, Solidificação transitória, microestrutura e propriedades de ligas Al-Ni, 2009 [tese doutorado]. Campinas: Departamento de Engenharia Mecânica, Universidade Estadual de Campinas; 2009.

* Contribuição técnica ao 69 Congresso Anual da ABM - Internacional e ao 14 ENEMET - Encontro Nacional de Estudantes de Engenharia Metalúrgica, de Materiais e de Minas, 21 a 25 de julho de 2014, São Paulo, SP, Brasil. 